\title{
Characterization of the protease domain of Rice tungro bacilliform virus responsible for the processing of the capsid protein from the polyprotein
}

\author{
Philippe Marmey ${ }^{1}$, Ana Rojas-Mendoza ${ }^{2}$, Alexandre de Kochko ${ }^{1}$, \\ Roger $\mathrm{N}$ Beachy ${ }^{3}$ and Claude $M$ Fauquet*3
}

Address: ${ }^{1}$ IRD, UMR «DGPC», B.P. 64501, 34394 Montpellier cedex 5, France, 2 Protein Design Group, Centro Nacional de Biotecnologia, Campus Universidad Autonoma Cantoblanco, 28049 Madrid, Spain and ${ }^{3}$ Donald Danforth Plant Science Center, 975 North Warson Road, St. Louis, MO 63132, USA

Email: Philippe Marmey - marmey@mpl.ird.fr; Ana Rojas-Mendoza - arojas@cnb.uam.es; Alexandre de Kochko - dekochko@mpl.ird.fr; Roger N Beachy - rnbeachy@danforthcenter.org; Claude M Fauquet* - iltab@danforthcenter.org

* Corresponding author

Published: 14 April 2005

Virology Journal 2005, 2:33 doi:10.1 I86/1743-422X-2-33

This article is available from: http://www.virologyj.com/content/2/I/33

(c) 2005 Marmey et al; licensee BioMed Central Ltd.

This is an Open Access article distributed under the terms of the Creative Commons Attribution License (http://creativecommons.org/licenses/by/2.0), which permits unrestricted use, distribution, and reproduction in any medium, provided the original work is properly cited.
Received: 29 March 2005

Accepted: 14 April 2005

\begin{abstract}
Background: Rice tungro bacilliform virus (RTBV) is a pararetrovirus, and a member of the family Caulimoviridae in the genus Badnavirus. RTBV has a long open reading frame that encodes a large polyprotein $(\mathrm{P} 3)$. Pararetroviruses show similarities with retroviruses in molecular organization and replication. P3 contains a putative movement protein (MP), the capsid protein (CP), the aspartate protease (PR) and the reverse transcriptase (RT) with a ribonuclease $H$ activity. $P R$ is a member of the cluster of retroviral proteases and serves to proteolytically process $\mathrm{P} 3$. Previous work established the $\mathrm{N}$ - and $\mathrm{C}$-terminal amino acid sequences of $\mathrm{CP}$ and $\mathrm{RT}$, processing of $\mathrm{RT}$ by $\mathrm{PR}$, and estimated the molecular mass of PR by western blot assays.
\end{abstract}

Results: A molecular mass of a protein that was associated with virions was determined by in-line HPLC electrospray ionization mass spectral analysis. Comparison with retroviral proteases amino acid sequences allowed the characterization of a putative protease domain in this protein. Structural modelling revealed strong resemblance with retroviral proteases, with overall folds surrounding the active site being well conserved. Expression in E. coli of putative domain was affected by the presence or absence of the active site in the construct. Analysis of processing of CP by PR, using pulse chase labelling experiments, demonstrated that the $37 \mathrm{kDa}$ capsid protein was dependent on the presence of the protease in the constructs.

Conclusion: The findings suggest the characterization of the RTBV protease domain. Sequence analysis, structural modelling, in vitro expression studies are evidence to consider the putative domain as being the protease domain. Analysis of expression of different peptides corresponding to various domains of $\mathrm{P} 3$ suggests a processing of $C P$ by PR. This work clarifies the organization of the RTBV polyprotein, and its processing by the RTBV protease. 


\section{Background}

Plant pararetroviruses are classified as members of the family Caulimoviridae which comprises 6 genera [1]. Like retroviruses, members of this group of viruses use reverse transcriptase for replication of the genome $[2,3]$. However, they differ in two major points: retroviruses have an RNA genome whereas pararetroviruses have a DNA genome; and, a proviral form of retroviruses is integrated into the host chromosome whereas the DNA of pararetroviruses accumulates within the nucleus as multiple copies of a circular chromosome [4].

Retroviruses and pararetroviruses show similarities in their molecular organization and replication process and are phylogenetically related. These groups of viruses direct the production of a terminally redundant RNA which is used as a replicative intermediate and as mRNA. Many of the genes encoded by pararetroviruses are homologous in sequence and/or analogous in function to those of retroviruses. The genome of all replication-competent retroviruses consists of three major genetic elements that are arranged in the order gag-pol-env (structural-replicationenvelope proteins). Each protein is produced as a result of frameshifting during translation, or suppression of stop codons in the polyproteins. Products of the gag ORF represent the structural components of the viral matrix, i.e. capsid and nucleocapsidproteins; the pol domains generally comprise the protease, reverse transcriptase, ribonuclease and an endonuclease/integrase. Pararetroviruses encode the gag-pol core, but lack an integrase, as viral DNA integration into the host chromosome is not required [5].

Retrovirus and pararetrovirus polyproteins are believed to be processed by their own aspartate proteases $[3,6,7]$. These proteases contain several conserved regions when compared with each other and share consensus sequences in the active site; however, they show no homology with other viral proteases. Protein cleavages by these and other proteases are dependant on amino acid sequence and conformation near the cleavage site [6].

Rice tungro is a major rice disease in southeast asia and is caused by a double infection by two viruses $[8,9]$ : Rice tungro bacilliform virus (RTBV) [10,11], a member of the genus Badnavirus in the family Caulimoviridae [1], and Rice tungro spherical virus (RTSV), a single-stranded RNA virus and member of the genus Waikivirus in the family Sequiviridae $[12,13]$. RTBV is responsible for symptoms of the disease [8] and RTSV is required for the transmission of the two viruses by the leafhopper vector Nephotettix virescens $[14,15]$.

RTBV genome is a double stranded DNA of $8.0 \mathrm{kbp}$ with two site-specific discontinuities resulting from replication by reverse transcriptase $[3,16]$. The RTBV genome has four open reading frames (ORF) [17]. ORF3 has similarities with the gag-pol core of retroviruses. The polyprotein (P3) contains a putative movement protein (MP), the capsid protein $(\mathrm{CP})$, the aspartate protease (PR), and the reverse transcriptase (RT) with a ribonuclease $\mathrm{H}$ activity. The $\mathrm{N}$ and $\mathrm{C}$ - terminal amino acid (aa) sequences of the $\mathrm{CP}$ were deduced from MALDI-TOF mass spectral analysis [18]. The location of the CP domain, which is encoded by aa 477-791 in P3, was confirmed by immunodetection reactions using antibodies raised against different segments of ORF3 [18]. P3 sequence aa 985-995 shows homologies to the active site of aspartate proteases encoded by retroviruses and pararetroviruses, with the sequence DSGS believed to be the RTBV protease active site. Changing of $\mathrm{D}$ to A (aspartic acid to an alanine) in this sequence affects the proteolytic processing of the RT [19]. Detection of RTBV gene products in vivo revealed a major protein of $13.5 \mathrm{kDa}$ in virus preparations, by using an antibody raised against the domain aa 881-1098 $[10,20]$. The antibody was used in immunogold labelling reactions and showed binding on the surface of the virus particle, suggesting that the PR is located at or near the surface of the virus particle [20].

In this paper, we used mass spectrometry analysis to characterize the RTBV protease domain in a protein associated with purified virions, and confirm the hypothesis by in silico modelling and in vitro expression studies. Analysis of products of in vitro processing of P3 suggests that RTBV aspartate protease is involved in the release of the $\mathrm{CP}$ from the polyprotein P3.

\section{Results}

\section{Determination of molecular mass}

In-line HPLC electrospray ionization was used to determine the molecular mass of proteins that were isolated in preparations of RTBV. Several peaks were observed using this method, none of which correspond to the known molecular mass of the CP subunits [18]. Many of the primary peaks were accompanied by low amounts of proteins of similar but not identical charge: we presumed that these peaks represented various charge statesof the peptide/protein. Reconstruction of the data, after algorithms were applied to convert the family of ion peaks, gave a protein with molecular mass of 13,794 \pm 4 Da (Figure 1). The lack of recovery or detection of proteins of the size of $\mathrm{CP}$ subunits is likely the result of retention on the HPLC column due to the very basic charge of the protein; estimated isoelectric point (pI) of CP is 9.43.

\section{Localization of the protease domain}

By comparing the known sequence of P3 protein in RTBV with aspartate proteases encoded by other retroviruses we predicted that five possible proteins could be derived with 


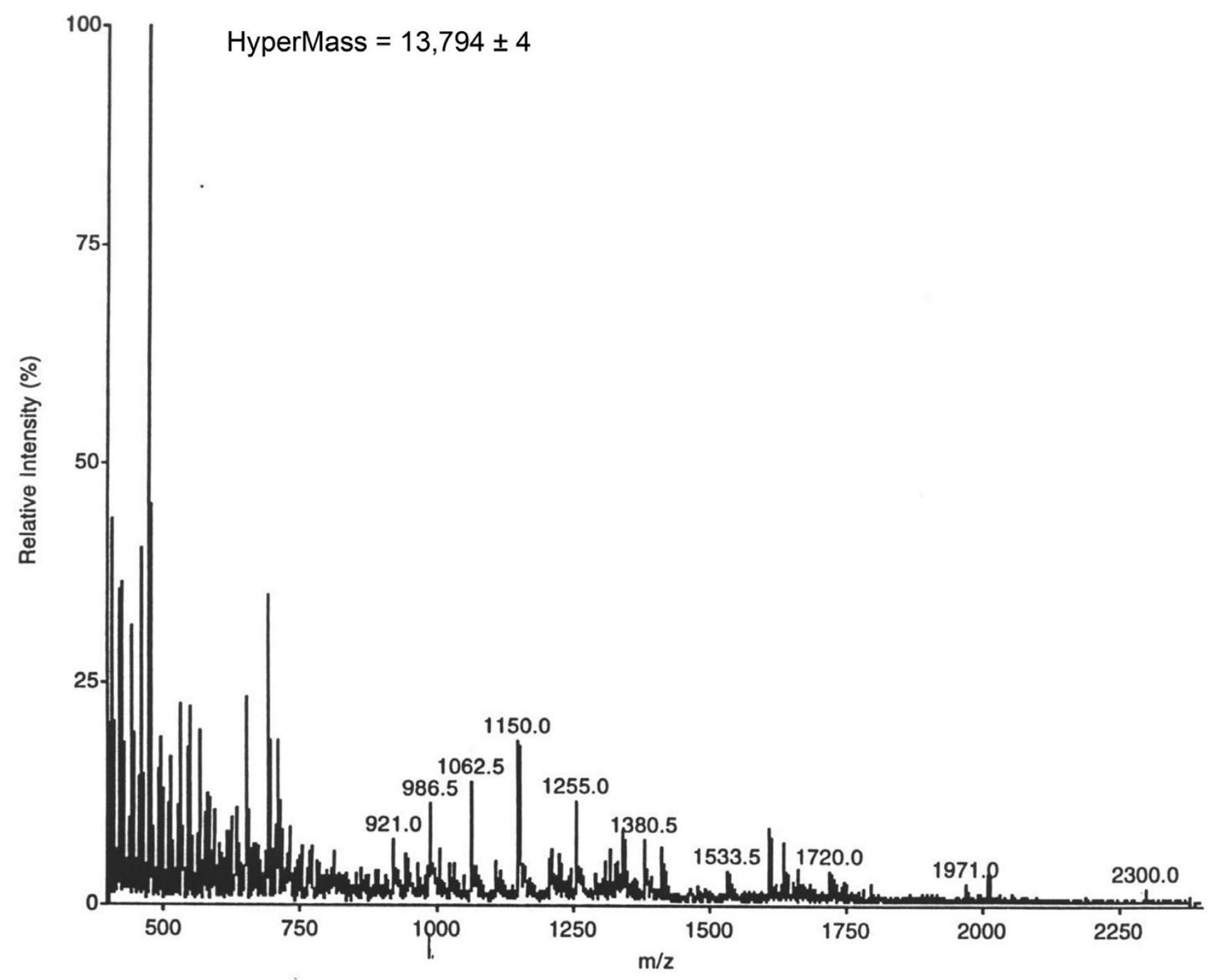

Figure I

Mass spectrometry analysis performed on RTBV virions. In-line HPLC electrospray ionization mass spectrometry analysis performed on RTBV virions. Virus sample was denatured with guanidium hydrochloride $4.8 \mathrm{M}$ prior, to injection onto the column. Analysis of peptide which coeluted from the in-line HPLC column in various charge states gave a molecular mass of 13,794 $\pm 4 \mathrm{Da}$.

a molecular mass of $13,794 \pm 4$ Da that could contain the putative active site domain DSGS (at aa 987-990) and the IIG sequence. The IIG sequence motif is conserved amongst retroviral proteases and is located at aa 10631065 in P3. The five predicted proteins (Figure 2) were covering amino acids 965-1085, 967-1086, 971-1091, 982-1102, and 984-1104, with predicted molecular masses of 13,790.71 Da, 13,790.71 Da, 13,796.7 Da, 13,791.7 Da and 13,795.7 Da, respectively. These predictions of the five domains are based on the combination of molecular mass and the presence of conserved motifs, and not on putative protease cleavage sites that flank the five predicted proteins.

\section{Structural model of the protease}

The overall sequence similarity between aspartate proteases is quite low (below 25\%) based on pairwise scoring criteria; therefore we applied fold recognition methods to detect remote homologues. The sequence alignment for the proteins selected for analysis showed strong conservation in the active site of the proteins (Figure 3 ). The pairwise alignment between the Rous sarcoma virus (RSV) 
(A)

965

$\downarrow$

(A)

AGCYVETKISFNNENRIITALIDSGSTHNII----PKPTKTFIIGHRFLTNENGSVTIHKDYITI

(B)

967

$\downarrow$

CYVETKISFNNENRI ITALIDSGSTHNII----PKPTKTFI IGHRFLTNENGSVTIHKDYITIQ

ITALIDSGSTHNII----PTKTFIIGHRFLTNENGSVTIHKDYITIQKTTGIYPTARHELKSE

984

$\downarrow$

Figure 2

Putative protease domains for RTBV. Position of five peptides that include the active protease domains with molecular mass that correspond to the mass spectrometry analysis. Peptide A has a predicted molecular mass of I3,790.7I kDa; peptide B of I3,790.7 I kDa; peptide C of I3,796.70 kDa; peptide D of 13,793.60 kDa; peptide E of I3,795.70 kDa. Underlined sequences represent the active site of the protease. The grey box indicates a conserved motif among retroviral proteases. Numbers above arrows indicate position of amino acids in P3.

template and the RTBV sequence was submitted to comparative modelling. As represented in the model (Figure 4), there is a strong resemblance between the structures predicted for RTBV and RSV proteases. The lack of identity in the predicted structures may be due to inherent inaccuracy of the modelling programs, due to inherent differences in the protein and substrate, and other characteristics. Taking these differences into account, as deduced by a folding assignment system [21] (where reliable scores were obtained) the protease sequence had a predicted folding structure that was highly similar to several other aspartate proteases. The overall fold surrounding the active site was well conserved between the putative RTBV protease and RSV protease used as template (Figures 3 and 4).

\section{Induction of putative protease domain}

Specific primers (Ab-PR-F and Ab-PR-R) were designed to amplify the putative protease domain deduced from the mass spectrometry analysis (Figure 2-A). DNA used for PCR amplification included the full-length RTBV clone pBSR63A, and plasmid pBS-mp/PR; the reactions led to isolation of peptide PR and mPR, respectively (Table 1 and Figure 5). PR and mPR differ from each other only at amino acid 987, in which the residue was changed from Aspartic acid (D) to Alanine (A). Peptides were expressed in $E$. coli and, following induction of gene expression the extracts were subjected to SDS-PAGE, and gels were stained with coomassie blue (Figure 6-A). The expected size of the peptides was about $14 \mathrm{kDa}$. We did not detect a protein in cultures that contain pTr-PR. However, in extracts of cultures containing $\mathrm{pTr}$-mPR, the protein $\mathrm{mPR}$ was easily detected at the expected position on the gel. Western immunoblot assays using antibodies raised against mPR (Ab-PR) confirmed that the $14 \mathrm{kDa}$ peptide was $\mathrm{MPR}$ (Figure 6-C).

\section{Analysis of the processing of polyprotein P3}

Pulse-chase labelling techniques were used to reveal possible processing of $\mathrm{P} 3$ by the protease in E. coli. After 1 hour induction cultures were labelled with ${ }^{35}$ S-methionine for five min after which protein extracts were subjected to SDS-PAGE, followed by autoradiography. Multiple bands were observed in cultures that contain each plasmid (Figure 7). Protein patterns represent peptides that are expressed and processed between 60 and 65 


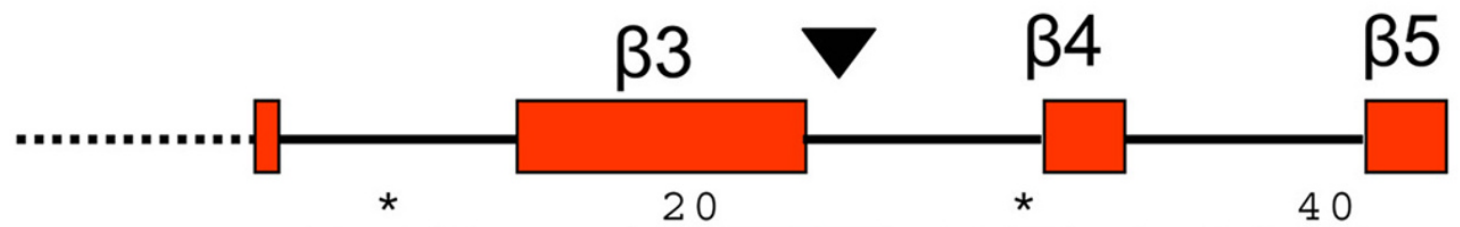

RSV : - - - TGSHPVKQRSVYITALLDTGADDTVISEEDWPTDWPVM RTBV : AGCYVETKISFNNENRI ITALIDSGSTHNIICPTLIPASWINN EIAV : - - - RPTTIVLINDTPLNVLLDTGADTSVLTTAHYNRLKYRG HIV : - - - RPLVTIKIGGQLKEALLDTGADDTILEEMSLPGRWKPK

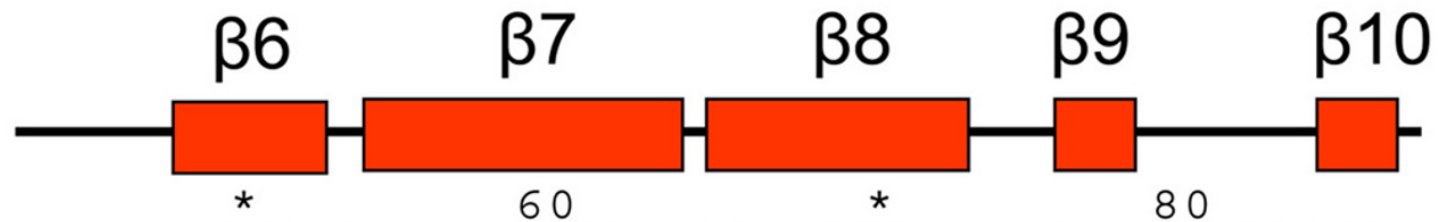

RSV : EAANPQIHGIGGGIPVRKSRDMIELGVINRDGSLE - - - RPLLL RTBV : THREIIMFAVDNSKYNLNQELIDDIKLQFQEVDETFGIKYKLG EIAV : RKYQGTGIG--.-----GVGGNVETFSTPVTIKKKGRHIKT HIV : M- - - - - - VGGIGGFIKVRQYDQILIEICG- - - - - HKAIG

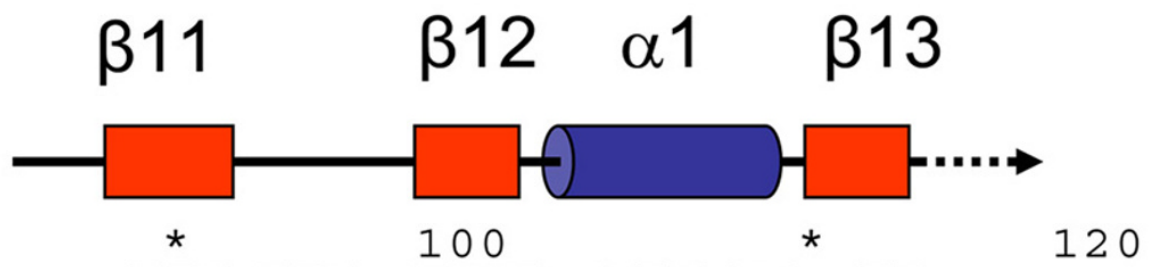

RSV : FPLVAMTPV- - NILGRDCLQGLGLRLT- - - - - RTBV : QTYVAPKPTKTFIIGHRFLTNENGSVTIHKDYTI EIAV : RMLVADIPVT--ILGRDILQDLGAKLVL - - - HIV : TVLVGPTPI - NIIGRNLLTQIGCTLNF - - - - -

\section{Figure 3}

Structural sequence alignment of the RTBV protease with other retroviral proteases. Sequence alignment of the RTBV protease amino acid sequence with proteases of Rous sarcoma virus (RSV), Equine infectious anemia virus (EIAV) and Human immunodeficiency virus (HIV). The color scheme corresponds to percentage of similarity (based on physico-chemical properties). Black background and white foreground indicate 100\%, grey background and white foreground indicate $80 \%$, grey background and black foreground indicate $60 \%$. Lower similarity values are not shown. Numbers over the alignment indicate the alignment length. Secondary structure elements from the RSV sequence are represented over the alignment. The numbering of the elements follows the RSV numbering based on structure. Boxes indicate beta strand elements assigned as $\beta$. The helix is represented as a cylinder and indicated as $\alpha$. Thick lines connecting the elements are loops and dashed lines indicate a break in the sequence. The black triangle indicates the location of the active site.

min after induction. Patterns of peptides induced from construct pET-MP-PR and pET-MP-mPR were very similar with one visible difference, namely the presence of a band at $37 \mathrm{kDa}$ in cells that contain pET-MP-PR. This band is absent in cells containing pET-MP-mPR, the plasmid with mutant PR. This difference was also observed between cultures that contain constructs pET-P3 and pET-mP3. The 37 $\mathrm{kDa}$ band was not present for the clone pET-MP and pET- 

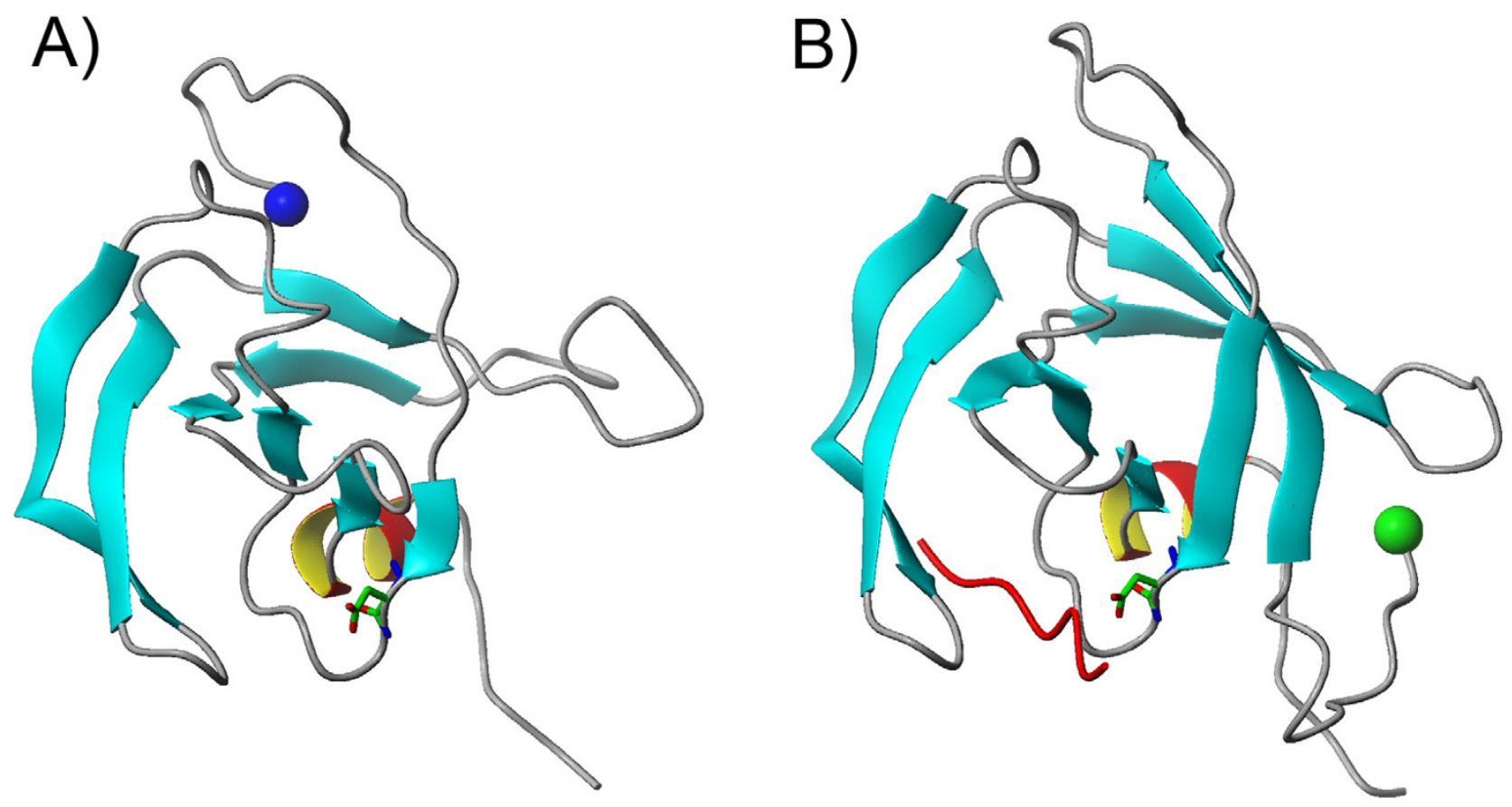

\section{Figure 4}

Structural modelling of the RTBV protease. Structural modelling of the RTBV protease (A), and Rous sarcoma virus (RSV) protease used as template (B). The sphere indicates the $\mathrm{N}$-terminal end, aspartic acid of active site is shown in the stick model. In red is the RSV protease inhibitor 39 coupled to the active site. The first residues of RTBV PR could not be modelled. Conservation of the active site and overall fold recognition analyses with modelling building show that the RTBV sequence resembles greatly a protease fold.

28 (no insert) but was in cells that contain constructs that code a peptide that contains the $\mathrm{CP}$ and the protease, i.e. pET-MP-PRand pET-P3.

\section{Discussion}

Retroviral proteases have been studied for many years as they are essential in the control of the replication of retroviruses. Retroviral proteases contain about 100 amino acids residues in length, and contain one copy of the active site Asp-Thr-Gly or Asp-Ser-Gly [22]. It was proposed that they are active as homo-dimers [23]. Crystallographic structures of Rous sarcoma virus (RSV) and Human immunodeficiency virus (HIV) showed that the PR of the viruses are dimeric, with two copies of the active site being brought into close proximity at the junction between the dimer partners $[24,25]$. To date, numerous retroviral proteases have been investigated, and their structures determined [26]. The retroviral protease is formed by duplication of four structural elements: a hair- pin, a wide loop, an $\alpha$-helix and a second hairpin. Active site sequences are placed in the extended loop of the structural model, implying that the active site is a number of amino acids away from the N-terminal of retroviral proteins.

The CP domain was previously characterized by MALDITOF (matrix-assisted laser desorption/ionization-time of flight) mass spectrometry analysis [18]. A single CP domain was identified, with positions of the amino- and carboxy-termini of the $\mathrm{CP}$ at aa 477 and 791, respectively. The molecular mass of the $\mathrm{CP}$ was determined to be 37,303 Da with an estimated pI of 9.43. A basic pI can explain the absence of peaks related to the $\mathrm{CP}$ in our mass spectral analysis. In this paper, virions of RTBV were subjected to in-line HPLC electrospray ionization mass spectrometry analysis. The HPLC column is expected to have retained the $\mathrm{CP}$ prior to mass spectrometry analysis. The molecular mass of the protein found by these analyses 
Table I: Methodology for creating the constructs used in the analysis

\author{
Cloning into pBlueScript KS \\ Clone pBS-CP/PR was obtained by using primers CP-PR-F and CP-PR-R on full-length RTBV clone pBSR63A and cloning the PCR fragment into \\ plasmid pBlueScript KS. \\ Clone pBS-PRI was obtained by digesting PBS-CP/PR with Xbal and Hindlll and cloning the 0.8 kbp fragment into plasmid pKS. \\ Clone pBS-mPRI was obtained by digesting PBS-mpr/RT 19 with Pstl and EcoRV and cloning the 0.7 kbp fragment into pBS-PRI digested with Pstl \\ and EcoRV. \\ Clone pBS-CP/mPR was obtained by digesting PBS-mPRI with Pstl and EcoRV and cloning the 0.7 kbp fragment into pBS-CP/PR digested with Pstl \\ and ECORV.

\section{Cloning into pTrHis.} \\ Clone pTr-CP/PR was obtained by digesting PBS-CP/PR with BamHI and Hindll and cloning the 2.5 kbp fragment into pTrHisA digested with \\ BamHl and Hindlll. \\ Clone PTr-PR was obtained was obtained by using primers Ab-PR-F and Ab-PR-Ron full-length RTBV clone pBSR63A and cloning the PCR \\ fragment into PTrHis A digested with Ncol and Hindlll. \\ Clone pTr-mPR was obtained by using primers Ab-PR-F and Ab-PR-R on plasmid pBS-mpr/RT and cloning the PCR fragment into $p T r H i s ~ A$ \\ digested with Ncol and HindllI.

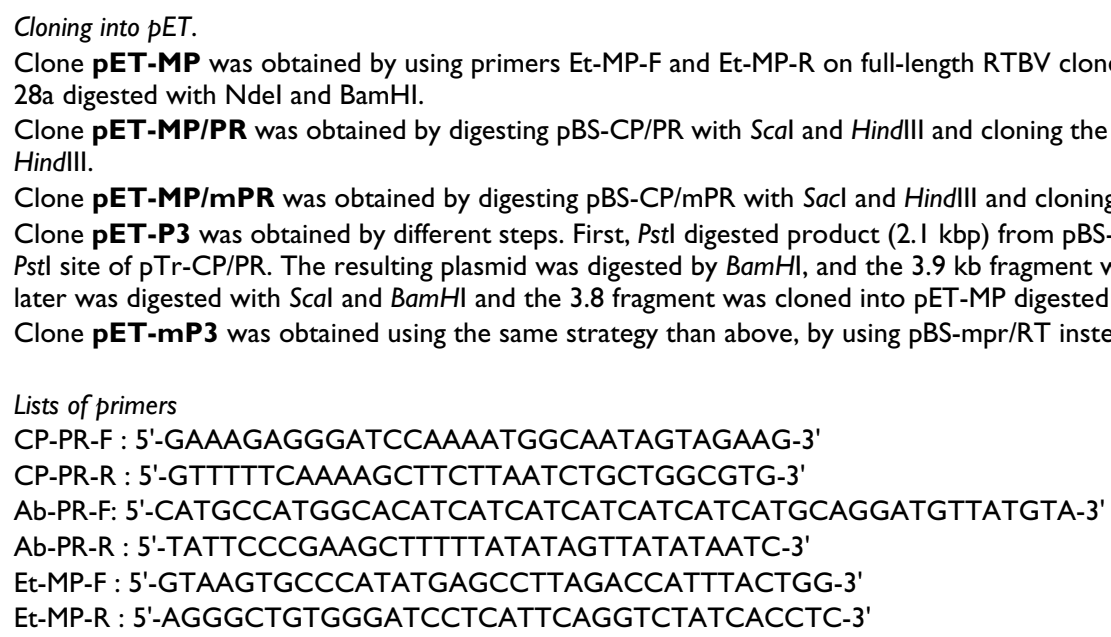

was determined to be $13,794 \pm 4 \mathrm{Da}$, with a putative isoelectric point of 6.3. We suspected that this protein was the viral protease that was encoded in P3 protein.

Five peptide domains, with the predicted mass of the protein identified in virions, were found to contain the active site DSGS, the active site of an aspartate protease, and the conserved region IIG (Figure 2). We compared the derived sequences of the five putative proteins with sequences of retroviral proteases, a process that led us to predict that the peptide comprising aa 965-1085 represents the protease, based on the position of the active site within the predicted sequence. In the predicted protein the Aspartic acid residue of active site would be 23 amino acid away from N-terminus; the active site is 25 and 37 aa from the N-terminus for HIV and RSV, respectively.

To confirm if the target sequence is or is not a protease, we used a combination of sequence and structural predictions procedures to build a structural model for the RTBV protease (Figure 4-A) with RSV protease as a template (Figure 4-B). The consistency in fold recognition was given by reliable scores against different templates for the same SCOP classification (SCOP classification b.50.1). The proteins of this fold show a closed beta barrel. In the model, some of the beta strands elements are missing, however the remaining beta sheets can be arranged in a predicted conformation as they are product of sequence duplications. Keeping in mind that the protease domain is part of a multi-domain protein, additional interactions among the domains may influence the folding of individual subunits. The conservation in the predicted active site, and the predicted overall folding of sequences led us to predict that the domain posseses a protease activity. Subsequent experiment evidence that confirmed that the predicted active site can be inactive by mutation of $\mathrm{D}$ to $\mathrm{A}$, the predicted secondary structure and the fold recognition analyses with model building led us to conclude that the protein comprises an aspartate protease. 


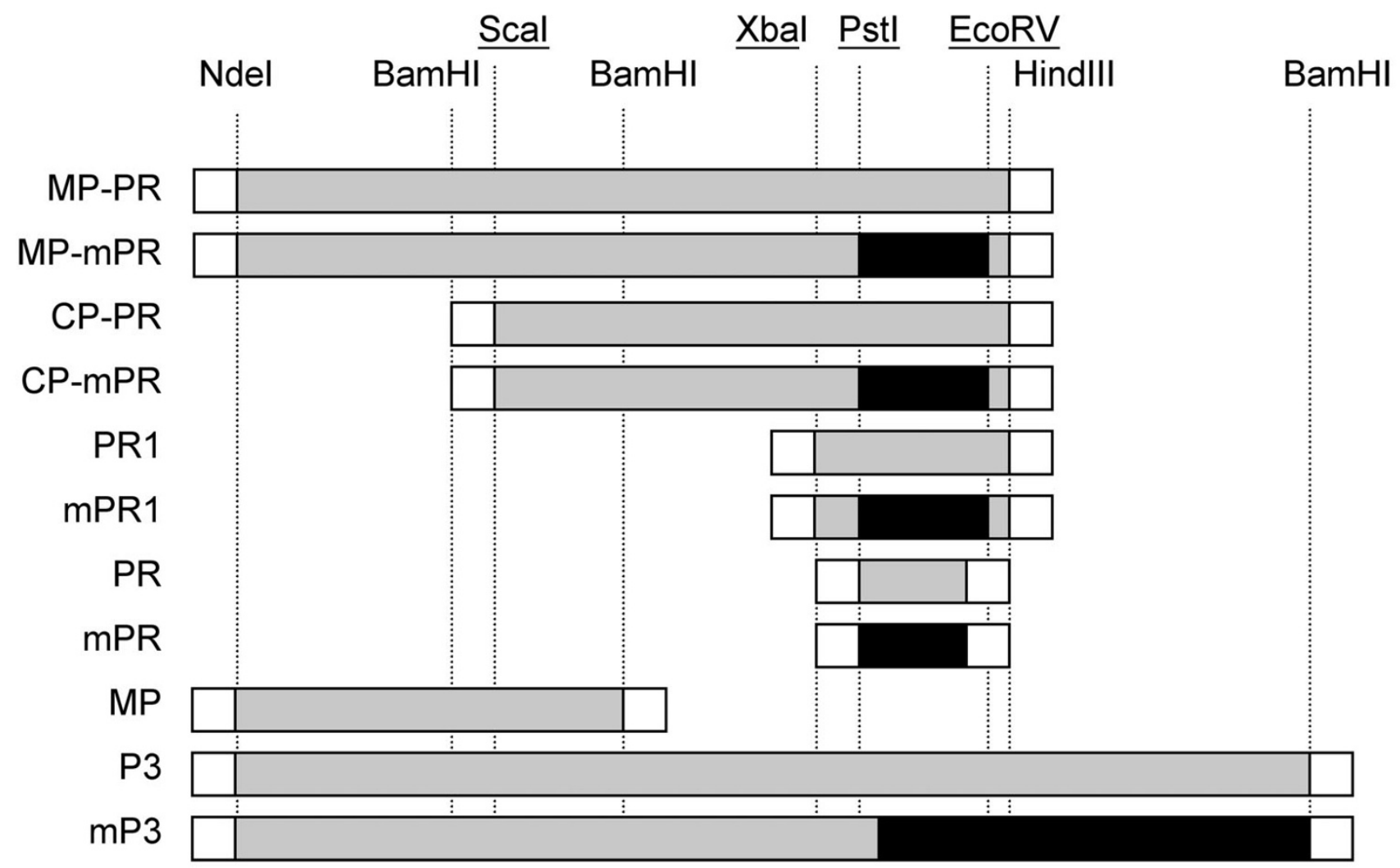

\section{Figure 5}

Polyprotein P3 peptide domains cloned in different constructs. Visualization of P3 peptide domains cloned in different constructs. Parts in grey are sequence derived from the full-length RTBV clone PBSR63A II. Parts in black are sequence imported from plasmid pBS-mp/RT 19, containing the protease mutated active site. Parts in white are sequences from vectors. Underlined restriction enzymes are sites that are present in ORF3.

Plasmids that encode peptides PR and mPR were introduced for expression in E. coli: however, PR did not accumulate in E.coli while mPR was expressed normally and reacted with Ab-RTBV and with Ab-PR antibodies. In other studies, the mutation of $\mathrm{D}$ to $\mathrm{A}$ in the active site of the RTBV protease was shown to affect its activity [19]. We suggest that PR did not accumulate in $E$. coli because the peptide was an active protease that was not tolerated in the host. Previous attempts to express proteases in E. coli have had similar outcomes $[27,28]$.

An antiserum against the region aa $881-1098$ of the P3 was produced in previous studies [20]; this peptide includes the protease domain. Using this antibody a protein of approximately $13.5 \mathrm{kDa}$ was detected by western blots assays in virus preparations and in infected tissues, suggesting that the protein that was detected represented the viral protease [20]. Furthermore, the antiserum was used to label virus particles, and revealed that the label was attached to virions. The characterization of PR domain, and the immunodetection reactions performed in the present studies are in agreement with the previous results, and also with studies performed by Marmey et al., [18], which investigated a peptide comprising aa 806-961 of P3, that was referred to as IR. IR did not react with AbRTBV serum, suggesting that the IR region did not contain sequences related to the CP. Our results support the hypothesis that peptide IR corresponds to the intervening region between $\mathrm{CP}$ and $\mathrm{PR}$, and that it may be involved in the processing of P3 [18]. With the present study the $\mathrm{N}$ and $\mathrm{C}$ - terminal amino acid sequences are now characterized for CP, PR and RT-Rnase H $[18,19]$. However, we did not identify apparent sequence similarities between the cleavage sites that would be used by the PR (Figure 8). Such a lack of sequence similarity is usual for viral aspartate proteases $[29,30]$. Other details that remain to beclarified in the organization of P3 include: 

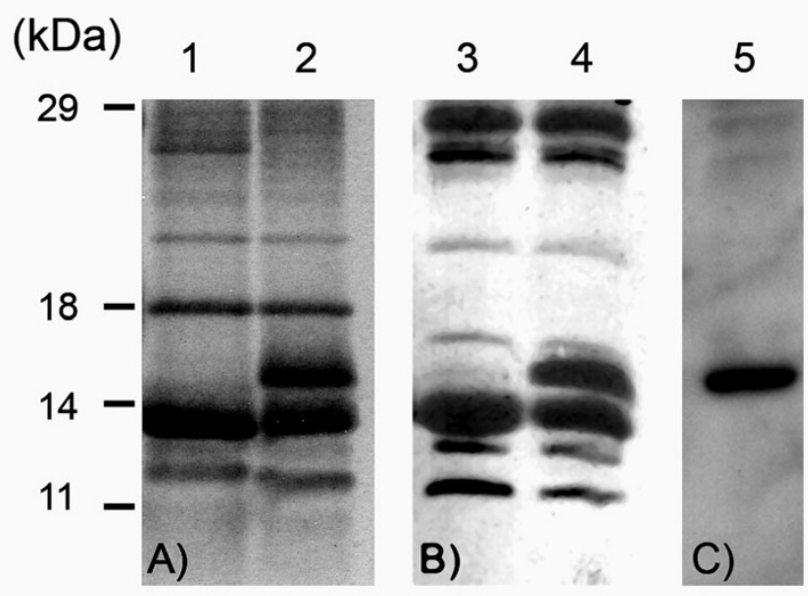

Figure 6

Induction of the putative protease domain. Expression of peptides in E.coli. Numbers on the left are estimated sizes in $\mathrm{kDa}$ of the molecular weight marker. (A) Coomassie bluestained gel of induced peptides in E.coli. Lane I: pTr-PR; Lane 2: pTr-mPR. (B) Western blot performed on induced peptides using antibodies raised against RTBV (Ab-RTBV). Lane 3: pTr-PR; Lane 4: pTr-mPR. (C) Western blot performed on induced peptides using antibodies raised against PR domain (Ab-PR). Lane 5: pTr-mPR. Peptide PR could not be induced from pTr-PR. pTr-mPR induced a specific peptide of about 14 $\mathrm{kDa}$, corresponding to the protease domain (with mutation), and recognized by Ab-PR.

characterization of the movement domain, and the order and rates in which the various sites on P3 are cleaved.

A previous work conducted in insect cells using baculovirus based constructs, including constructs in which the active site of the protease was mutated revealed that RT was processed by PR [19]. In the present work, in vitro processing of CP by PR was demonstrated in E.coli. If immunoprecipitations with antibodies were not achieved for technical reasons, presence of the $37 \mathrm{kDa}$ peptide was associated with co-existence of $\mathrm{CP}$ and active PR in the construct. It is the first time that such a processing is demonstrated for pararetroviruses (e.g. Commelina yellow mottle virus, Banana streak virus, Cacao swollen shoot virus), where CP and PR are components of the same polyprotein.

Our results clarify the organization of $\mathrm{P} 3$, and its processing by its own protease and lead to a more complete understanding of the replication process and possible points of control of pararetroviruses.

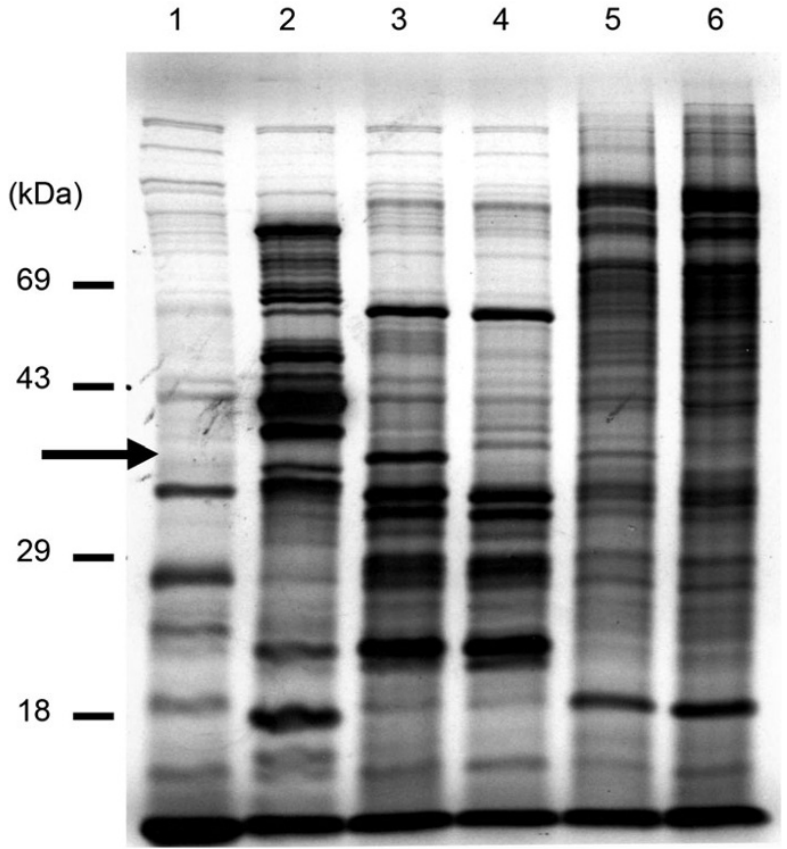

\section{Figure 7}

In vitro releasing of the coat protein from the polyprotein P3. Autoradiography of an SDS-PAGE of induced peptides from different $P E T$-vectors induced in $E$. coli. ${ }^{35 S}$ radiolabelled methionine was added for 5 minutes after 60 minutes of induction with IPTG. Numbers (in $\mathrm{kDa}$ ) on the left indicate mobility of the molecular weight markers. Lane I: pET(no insert); Lane 2: pET-MP; Lane 3: pET-MP-PR; Lane 4: pET-MP-mPR; Lane 5: pET-P3; Lane 6: pET-mP3. Arrow shows the presence of a peptide (estimated molecular mass of $37 \mathrm{kDa}$ ) that is present only for constructs that code a peptide that contains the coat protein and the protease (pET-MP-PR; pET-P3).

\section{Methods}

\section{RTBV strain used for the analysis}

The RTBV strain used for the analysis was from the International Rice Research Institute (IRRI, Los Banos, Philippines). Sequence of the genome was published [11], with accession number [GenBank:M65026].

\section{Mutation of the active site of protease}

Plasmid pBS-mp/RT [19] contain the putative mutated protease and reverse transcriptase of RTBV. The aspartic acid in the sequence DSGS (RTBV P3, amino acid 987) was changed to alanine, resulting in the sequence ASGS. Plasmid pBS-mp/RT was used for further sub-cloning.

\section{Analysis by mass spectrometry}

In-line HPLC electrospray ionization mass spectrometry [31] was employed. The experimental protocol was 


$\begin{array}{llllllllllllllll}\text { P7 } & \text { P6 } & \text { P5 } & \text { P4 } & \text { P3 } & \text { P2 } & \text { P1 } & \text { P1' P2' P3' P4' } 1 \text { 5' P6' P7' } \\ & & & & & & & & & & & & & \\ \text { S } & \text { T } & \text { S } & \text { S } & \text { E } & \text { I } & \text { R } & \text { P } & \text { T } & \text { K } & \text { R } & \text { P } & \text { K } & \text { E } & \text { IR/CP } \\ \text { N } & \text { R } & \text { C } & \text { P } & \text { R } & \text { R } & \text { Y } & \text { T } & \text { N } & \text { Q } & \text { A } & \text { R } & \text { A } & \text { S } & \text { CP/IR } \\ \text { K } & \text { T } & \text { S } & \text { I } & \text { N } & \text { K } & \text { T } & \text { A } & \text { G } & \text { C } & \text { Y } & \text { V } & \text { E } & \text { T } & \text { IR/PR } \\ \text { H } & \text { K } & \text { D } & \text { Y } & \text { I } & \text { T } & \text { I } & \text { Q } & \text { K } & \text { T } & \text { T } & \text { G } & \text { I } & \text { Y } & \text { PR/IR } \\ \text { P } & \text { Q } & \text { P } & \text { I } & \text { L } & \text { G } & \text { Y } & \text { K } & \text { N } & \text { E } & \text { I } & \text { G } & \text { N } & \text { Q } & \text { IR/RT-Rnase H } \\ \text { E } & \text { G } & \text { D } & \text { F } & \text { I } & \text { L } & \text { K } & \text { C } & \text { L } & \text { Q } & \text { N } & \text { P } & \text { D } & \text { S } & \text { RT-Rnase H/IR }\end{array}$

Figure 8

Protease cleavage site sequences in the RTBV polyprotein P3. Protease cleavage site sequences in the RTBV polyprotein P3. The designation of amino acid residues spanning the cleavage site is according to [40]. MP: movement protein; IR: intervening region; CP: capsid protein; PR: Protease; RT: Reverse transcriptase ; Rnase H: Ribonuclease $\mathrm{H}$. Cleavage site sequences MP/IR has not been determined yet. A lack of significant sequence similarities is observed, a characteristic of aspartate proteases.

similar to that described [19]. MacBioSpec algorithms (Sciex) were used to convert the family of ion peaks, which result from the protein being in various charge states, to an accurate molecular mass. Virus sample was denatured with guanidium hydrochloride at $4.8 \mathrm{M}$ prior to injection onto the column.

\section{Sequence and structural prediction analyses}

The RTBV sequence was used as a query for the BLAST program against non redundant databases and PDB databases. No significant hits were identified with suitable evalues by these queries. The sequence was then submitted to fold recognition methods at the metaserver http://gen esilico.pl[32]. Reliable templates were found with high scores, all of which were found in retroviral proteases (all beta proteins: SCOP classification b.50.1.1). Several pairwise alignments between RTBV and templates were checked using SQUARE [33] and further submitted to homology modelling using the Swissmodel program [34]. Models were evaluated using PSQS http://www1.jcsg.org/ psqs/[35] and Whatif http://www.cmbi.kun.nl/gv/serv ers/[36] tools. The structure of the Rous sarcoma virus (RSV) protease (pdb code 1bai_A) provided the best model as a viral aspartate protease and was chosen for this purpose. Illustrations for the model were generated using MolMol [37].

\section{Constructions of plasmids}

The full-length RTBV clone pBSR63A [11] was used as DNA matrix for PCR reactions to amplify specific regions of ORF3 using specific primers that were designed to amplify specific sequences from the RTBV genome. Con- structs were obtained by cloning the PCR fragments into vectors and/or by cloning fragments obtained after digestion of constructs with restriction enzymes and pBS-mp/ PR (Table 1). Cloning was conducted in pBluescript KS vector (Stratagene/USA), in pTrHis vector (Invitrogen/ USA) and in pET vector (Novagen/USA). Restriction enzymes were used according to manufacturer (GibcoBRL, USA).

\section{Expression of proteins}

All pTrHis based vectors were transformed into E.coli DH5- $\alpha$. The resulting plasmids were designated pTr-PR, pTr-mPR and resulted in synthesis of peptides, named PR, $\mathrm{mPR}$, corresponding to regions between residues 9651085 (Figure 5), with plasmid pTr-mPR encoding peptide with amino acid 987 mutated from D to A.

\section{Analysis of in vitro processing}

All pET vectors were transformed into E.coli BL21/DE3 (pLys S). The resulting plasmids were designated pET-MP, pET-MP/PR, pET-P3, pET-MP/mPR, pET-mP3. These plasmids encode (in order) peptides, named MP, MP-PR, P3, MP-mPR, $\mathrm{mP3}$ corresponding to regions between residues 1-606, 1-1195, 1-1675, 1-1195, 1-1675, respectively (Figure 5). Plasmids pET-MP/mPR and pET mORF3 encode peptides with amino acid 987 mutated from $D$ to A. Bacteria were induced with IPTG in M9 salts medium, using rifampicin and an amino acid mixture that lacks methionine. At 60 minutes, ${ }^{35} \mathrm{~S}$ radiolabelled methionine was added for five minutes. Bacteria were centrifuged for three minutes and resuspended in Laemli sample buffer 
[38]. Samples were subjected to electrophoresis, the gel was dried and exposed to $\mathrm{x}$-ray film overnight.

\section{Antibodies and Western blot analysis}

Antibodies were obtained as previously described [18]. Peptide mPR, corresponding to region between residues 965-1085 and expressed with construct pTr-mPR, was used to produce Ab-PR. An antiserum (Ab-RTBV) was also raised against purified virions. Proteins were subjected to electrophoresis in SDS/PAGE, and transferred to a nitrocellulose membrane. The blot was incubated with antiserum at a 1:1000 dilution. Immunogenic proteins were detected using an alkaline phosphatase goat anti-rabbit IgG at 1:10000 dilution. Proteins were visualized in the presence of nitroblue tetrazolium and 5-bromo-4-chloro3-indoyl phosphate, or using the Biomax chemiluminescent detection system (Kodak/USA).

\section{Competing interests}

The author(s) declare that they have no competing interests.

\section{Authors' contributions}

PM carried out the designing of primers, the construction of various plasmids, the in vitro expression analysis and pulse chase labelling experiments; ARM performed the structural modelling analysis; AdK analyzed various sequences by computer; RNB and CMF were principal investigators. All authors read and approved the final manuscript.

\section{Acknowledgements}

We thank Dr. S.B.H. Kent for performing mass spectral analysis, and Dr. F. Mathieu-Daudé for critical reading of the manuscript. Work was performed at The Scripps Research Institute in ILTAB (International Laboratory for Tropical Agricultural Biotechnology).

\section{References}

I. Hull R, Geering A, Harper G, Lockhart BE, Schoelz JE: Caulimoviridae. In Virus Taxonomy, VIIIth Report of the ICTV Edited by: Fauque C.M. MMAMJDUBLA. London , Elsevier/Academic Press; 2005:385-396.

2. Takatsuji H, Hirochika H, Fukushi T, Ikeda J: Expression of cauliflower mosaic virus reverse transcriptase in yeast. Nature 1986, 3 1 9:240-243.

3. Laco GS, Beachy RN: Rice tungro bacilliform virus encodes reverse transcriptase, DNA polymerase and ribonuclease $\mathbf{H}$ activities. Proceedings of the National Academy of Sciences of the USA 1994, 9 I:2654-2658.

4. Rothnie HM, Chapdelaine $\mathrm{Y}$, Hohn T: Pararetroviruses and retroviruses: a comparative review of viral structure and gene expression strategies. Adv Virus Res 1994, 44: I-67.

5. Hohn T, Fütterer J: The proteins and functions of plant pararetroviruses : knowns and unknowns. Critical Review in Plant Sciences 1997, I 6(1):133-161.

6. Oroszlan S, Luftig RB: Retroviral proteinases. In Current Topics in Microbiology and Immunology Volume 157. Berlin, Heidelberg, SpringerVerlag; 1990:153-185.

7. Torruella M, Gordon K, Hohn T: Cauliflower mosaic virus produces an aspartic proteinase to cleave its polyproteins. Embo J 1989, 8(10):2819-2825.
8. Hibino H, Roechan M, Sudarisman S: Association of two types of virus particules with Penyakit Habang (Tungro Disease) of rice in Indonesia. Phytopathology 1978, 68:1412-1416.

9. Jones MC, Gough K, Dasgupta I, Subba Rao BL, Cliffe J, Qu R, Shen P, Kaniewska M, Blakebrough M, Davies JW, Beachy RN, Hull R: Rice tungro disease is caused by an RNA and a DNA virus. Journal of General Virology 199I, 72:757-76।.

10. Hay JM, Jones MC, Blakebrough ML, Dasgupta I, Davies JW, Hull R: An analysis of the sequence of an infectious clone of rice tungro bacilliform virus, a plant pararetrovirus. Nucleic Acids Research 1991, 19(10):2615-2621.

II. Qu R, Bhattacharyaa M, Laco G, Kochko de A, Subba Rao BL, Kaniewska M, Elmer JS, Rochester DE, Smith CE, Beachy RN: Characterization of the genome of rice tungro bacilliform virus: comparison with commelina yellow mottle virus and caulimoviruses. Virology I99I, I 85(I):354-364.

12. Shen P, Kaniewska M, Smith C, Beachy RN: Nucleotide sequence and genomic organization of rice tungro spherical virus. Virology 1993, I 93:621-630.

13. Le Gall O, Iwanami Y, Karasev AE, Jones T, Lehto K, Sanfaçon H, Wellink J, Wetzel T, Yoshikawa N: Sequiviridae. In Virus Taxonomy, VIIlth Report of the ICTV Edited by: Fauquet C.M. MMAMJDUBLA. London , Elsevier/Academic Press; 2005:793-798.

14. Hibino $\mathrm{H}$ : Relations of rice tungro bacilliform and rice tungro spherical viruses with their vector Nephotettix virescens. Ann Phytopath Soc Jap 1983, 49(4):545-553.

I5. Hibino $\mathrm{H}$ : Transmission of two rice tungro-associated viruses and rice waika virus from doubly or singly infected source of plants by leafhopper vectors. Plant Disease 1983, 67:774-777.

16. Bao Y, Hull R: Replication intermediates of rice tungro bacilliform virus DNA support a replication mechanism involving reverse transcription. Virology 1994, 204:626-633.

17. Hull R: Molecular biology of rice tungro viruses. Annual Review of Phytopathology 1996, 34:275-297.

18. Marmey P, Bothner B, Jacquot E, de Kochko A, Ong CA, Yot P, Siuzdak G, Beachy RN, Fauquet CM: Rice tungro bacilliform virus open reading frame 3 encodes a single 37-kDa coat protein. Virology 1999, 253:319-326.

19. Laco GS, Kent SBH, Beachy RN: Analysis of the proteolytic processing and activation of the rice tungro bacilliform virus reverse transcriptase. Virology 1995, 208:207-2।4.

20. Hay J, Grieco F, Druka A, Pinner M, Lee SC, Hull R: Detection of rice tungro bacilliform virus gene products in vivo. Virology 1994, 205(2):430-437.

21. Kurowski MA, Bujnicki JM: Genesilico protein structure prediction metaserver. Nucleic Acid Research 2003, 3 I:3305-3307.

22. Yasunaga T, Sagata N, Ikawa Y: Protease gene structure and env gene variability of the AIDS virus. FEBS Lett 1986, I99(2): | $45-150$.

23. Pearl LH, Taylor WR: A structural model for the retrovira proteases. Nature 1987, 329(6 I 37):35I-354.

24. Miller M, Jaskolski M, Rao JK, Leis J, Wlodawer A: Crystal structure of a retroviral protease proves relationship to aspartic protease family. Nature 1989, 337(6207):576-579.

25. Navia MA, Fitzgerald PM, McKeever BM, Leu CT, Heimbach JC, Herber WK, Sigal IS, Darke PL, Springer JP: Three-dimensional structure of aspartyl protease from human immunodeficiency virus HIV-I. Nature 1989, 337(6208):615-620.

26. Wlodawer A, Gustchina A: Structural and biochemical studies of retroviral proteases. Biochim Biophys Acta 2000, I477( I2): 16-34.

27. Laco GS, Fitzgerald MC, Morris GM, Olson AJ, Kent SB, Elder JH: Molecular analysis of the feline immunodeficiency virus protease: generation of a novel form of the protease by autoproteolysis and construction of cleavage-resistant proteases. Virol I997, 7 I (7):5505-55 I I

28. Rose JR, Salto R, Craik CS: Regulation of autoproteolysis of the HIV-I and HIV-2 proteases with engineered amino acid substitutions. J Biol Chem 1993, 268( I 6): I I939-I I945.

29. Poorman RA, Tomasselli AG, Heinrikson RL, Kezdy F): A cumulative specificity model for proteases from human immunodeficiency virus types I and 2, inferred from statistical analysis of an extended substrate data base. I Biol Chem I991, 266(22): |4554-|456|.

30. Pettit SC, Michael SF, Swanstrom R: The specificity of the HIV-I protease. Perspect Drug Discovery Design 1993, I:69-83. 
31. Chait BT, Kent SBH: Weighing naked proteins: Practical highaccuracy mass measurement of peptides and proteins. Science 1992, 257:1885-1894.

32. Fold Prediction Metaserver [http://genesilico.pl]

33. Tress ML, Jones $D$, Valencia A: Predicting reliable regions in protein alignments from sequence profiles. J Mol Biol 2003, 330(4):705-718.

34. Schwede T, Kopp J, Guex N, Peitsch MC: SWISS-MODEL: An automated protein homology-modeling server. Nucleic Acids Res 2003, 3 I(13):338I-3385.

35. Protein Structure Quality Score [http://wwwl.jcsg.org/psqs/]

36. Centre for Molecular and Biomolecular Informatics [http:// www.cmbi.kun.nl/gv/servers/]

37. Koradi R, Billeter M, Wuthrich K: MOLMOL: a program for display and analysis of macromolecular structures. J Mol Graph 1996, I4(I):5I-5, 29-32.

38. Laemmli UK: Cleavage of the structural proteins during the assembly of the head of the bacteriophage T4. Nature 1970 227:680-685.

39. Wu J, Adomat JM, Ridky TW, Louis JM, Leis J, Harrison RW, Weber IT: Structural basis for specificity of retroviral proteases. Biochemistry 1998, 37(13):4518-4526.

40. Berger A, Schechter I: Mapping the active site of papain with the aid of peptide substrates and inhibitors. Philos Trans $R$ Soc Lond B Biol Sci 1970, 257(8 I 3):249-264

Publish with Bio Med Central and every scientist can read your work free of charge

"BioMed Central will be the most significant development for disseminating the results of biomedical research in our lifetime. "

Sir Paul Nurse, Cancer Research UK

Your research papers will be:

- available free of charge to the entire biomedical community

- peer reviewed and published immediately upon acceptance

- cited in PubMed and archived on PubMed Central

- yours - you keep the copyright

Submit your manuscript here:

http://www.biomedcentral.com/info/publishing_adv.asp
BiolMedcentral 